\title{
Nem você acreditava que este lance daria tão certo, Carlos Grossman!
}

\author{
Neither had you believed that this move would work so well, Carlos Grossman! \\ ¡Ni usted creía que esta jugada sería tan seguro, Carlos Grossman!
}

José Mauro Ceratti Lopes. Grupo Hospitalar Conceição (GHC). Porto Alegre, RS, Brasil. jmauro.lopes@terra.com.br (Autor correspondente)

Bianca Niemezewski Silveira. Pontifícia Universidade Católica do Rio Grande do Sul (PUCRS). Porto Alegre, RS, Brasil. bianca.silveira@acad.pucrs.br Eduardo Aires de Oliveira. Pontifícia Universidade Católica do Rio Grande do Sul (PUCRS). Porto Alegre, RS, Brasil. eduardo.aires@acad.pucrs.br Francisco Souza Santos. Pontifícia Universidade Católica do Rio Grande do Sul (PUCRS). Porto Alegre, RS, Brasil. francisco.santos.002@acad.pucrs.br

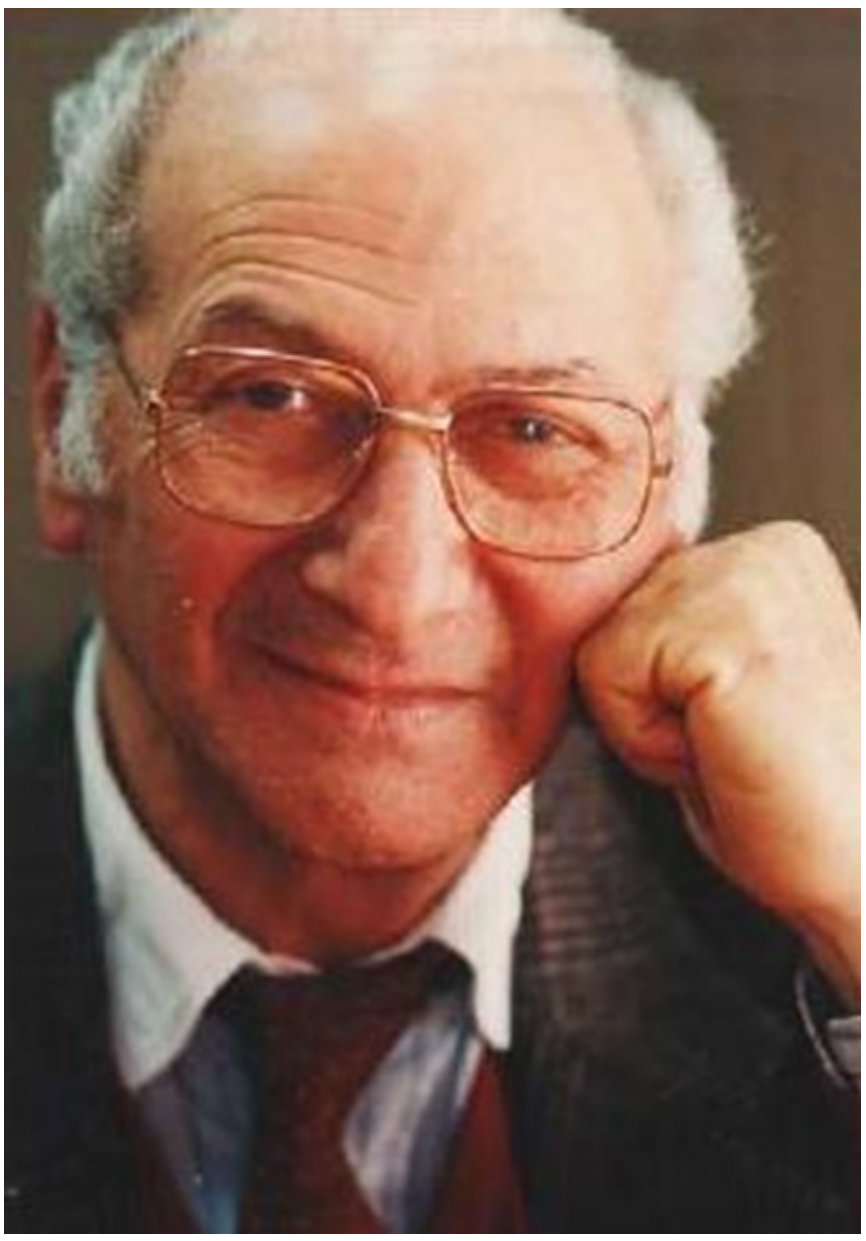

Mais do que um médico, Dr. Carlos Grossman é um sábio que, como ele mesmo diz, soube aproveitar bem todas as oportunidades que a vida lhe proporcionou.
Filho de imigrantes russos, Carlos Grossman nasceu no dia 2 de janeiro de 1928 em Porto Alegre. A escolha pela medicina não foi simples. A profissão do pai - agrônomo e pesquisador - sempre lhe trouxe a certeza de que cursaria agronomia; entretanto, nos meses que antecederam a inscrição para as provas, Grossman começou a considerar a possibilidade de cursar medicina. Escolheu ambos, porém agronomia foi colocada como segunda opçáo. Para sua surpresa, Grossman foi aprovado em primeiro lugar no vestibular da Universidade Federal do Rio Grande do Sul (UFRGS) de fevereiro de 1946 e, apesar de as dúvidas persistirem, deu início ao curso de Medicina.

Ao longo do curso, Carlos pouco expressou sua face humanista que tanto diferenciou posteriormente sua atuação - talvez pelo fato de que na época não era realizada a prática do estágio obrigatório pelas faculdades de medicina. Foi num estágio opcional na Santa Casa de Misericórdia de Porto Alegre que Grossman conheceu o professor Maurício Seligmann, o qual promoveu o contato do jovem com os pacientes, despertando, talvez pela primeira vez, o interesse deste pela medicina.

Em 1951, Grossman formou-se e foi visitar a família nos Estados Unidos. Neste período, solicitou bolsas de estudo em genética e estatística - não havia, afinal, desistido inteiramente da pesquisa - e, enquanto esperava o resultado, observou que, naquele país, os médicos somente consideravam-se preparados a exercer a medicina após fazerem especializaçấo através da residência - no Brasil, só havia tais programas no Rio de Janeiro e em São Paulo. Grossman se inscreveu na residência de Medicina Interna, em Washington, e teve como preceptor John Fitzgerald 
Smith, renomado internista que discutia casos complexos com seus alunos, contribuindo fortemente para a formação da personalidade médica de Grossman. No segundo ano de residência, chegou resposta em relaçáo a um de seus pedidos de bolsa: havia sido aprovado, mas recusou. Já havia se decidido pela medicina.

De volta ao Brasil, na década de 60, junto de Eduardo Faraco e Rubem Maciel, Grossman participou da criação da primeira Residência Médica do Rio Grande do Sul na UFRGS. Depois disso, tendo em vista a sua residência nos EUA e a sua experiência nessa criação, em 1975, Ellis Busnello e Isaac Lewin o convidaram para elaborar uma das primeiras Residências em Medicina de Família e Comunidade (MFC) do Brasil, no Centro de Saúde Escola Murialdo.

Em 1979, Grossman retornou ao Hospital Nossa Senhora da Conceição (HNSC) - onde já havia sido diretor por um breve período em 1973, quando se afastou por discordar da demissão injusta de uma auxiliar de enfermagem - para coordenar todos os programas de residência médica do Grupo Hospitalar Conceição (GHC). Assim, "com a faca e o queijo na mão" - como relata Grossman - criou a residência em MFC do GHC. Percebendo a necessidade de locais para os residentes atuarem, unido a Carlos Dora e José Mauro Lopes, Grossman em 1982 coordenou a implementação da Unidade de Medicina de Família do HNSC, a qual culminou na implementação do Serviço de Saúde Comunitária (SSC) com doze Unidades de Saúde da Família em Porto Alegre. Grossman ressalta que todas essas iniciativas deram certo devido ao empenho dos profissionais que o fizeram pela satisfação em melhorar a saúde pública. No início da década de 90, avaliadores do Ministério da Saúde visitaram o SSC, impressionaram-se com a qualidade dos serviços ali prestados e usaram-no como modelo para criar, em 1993, o Programa Saúde da Família, auxiliando ainda mais no desenvolvimento da MFC.

Para Grossman, o médico de família e comunidade deve ser a "porta de entrada do SUS": conhece e é conhecido por todos, é acessível à população e geralmente acerta seus diagnósticos. Para isso, é preciso que o médico seja qualificado e permaneça em sua comunidade. Tendo isso em vista e o fato de que, para ele, "aprender a atender é ver atender", compreendemos por que ele aproveitou todas as oportunidades que teve para criar novas residências médicas e auxiliar na qualificação dos médicos em formação.

Além dessa trajetória de grandes feitos, Grossman também é muito conhecido pelo seu senso crítico e por seus ensinamentos. Para ele, há três questóes cruciais para uma boa saúde: alta qualidade dos serviços, baixo custo e fácil acesso pelas pessoas. Sabendo da dificuldade de superar esses desafios na prática, ele sugere que "se use mais a cabeça (referindo-se ao aprimoramento dos exames realizados durante a consulta) e menos a caneta (diminuir gastos com exames, remédios e internaçôes)".

Outro legado de Grossman - marcado pelo seu bom-humor e sabedoria - é o de que a medicina também "se faz muito com a bunda", pois, segundo ele, quem náo tem tempo de sentar e ouvir o que o paciente tem a dizer devia fazer outra coisa. Ressalta também a importância de acreditar no que se ouve a fim de criar um vínculo de confiança com o paciente. Pensando nisso, podemos entender os seus "princípios": (1) O paciente sempre tem razão; (2) O paciente sempre diz a verdade; (3) Sempre é orgânico; (4) Sempre duvide de si mesmo.

Hoje, ele possui um consultório no Hospital Moinhos de Vento, onde atua como clínico geral, e é instrutor de Residência de MFC no GHC. De maneira descontraída e divertida, Carlos Grossman resume sua vida até o momento como uma surpresa boa, a qual inclusive se encontra registrada numa inscrição feita em uma placa em sua homenagem pela equipe da Unidade de Saúde Floresta que diz: "Nem você acreditava que este lance daria tão certo!". ${ }^{1-5}$

\section{Referências}

1. Silveira BN, Aires E, Santos FS. Entrevista com Carlos Grossman. Porto Alegre; 12 Jun 2012.

2. Camargo JJ. Palavra de Médico: "A dança dos modelos". Porto Alegre: Zero Hora; 5 Maio 2012. Vida, n. 1,070, p. 2.

3. Lenz MLM, Langoni P. Boletim Informativo do SSC (O BIS). Out 2004

4. Médicos gaúchos são elogiados. Porto Alegre: Zero Hora, 24 Abr 2008. Geral, p. 47.

5. Pena A. Entrevista com Carlos Grossman. Entrevista concedida a Andrea Pena para a elaboração do Boletim Eletrônico sobre os homenageados. $9^{\circ}$ Congresso da Sociedade Brasileira de Medicina de Família e Comunidade. Fortaleza; 2008. [Via e-mail]. 